\title{
Genetically predicted C-reactive protein associated with breast cancer risk: interrelation with estrogen and cancer molecular subtypes using a Mendelian randomization
}

Su Yon Jung ( $\sim$ sjung@sonnet.ucla.edu )

University of California Los Angeles https://orcid.org/0000-0002-0513-1830

Jeanette C. Papp

University of California Los Angeles

Eric M. Sobel

University of California Los Angeles

Matteo Pellegrini

University of California Los Angeles

Herbert Yu

University of Hawai'i Cancer Center

Zuo-Feng Zhang

University of California Los Angeles

Research article

Keywords: genetically driven C-reactive protein, Mendelian randomization, obesity, exogenous estrogen, breast cancer subtypes by hormone receptor and HER2/neu.

Posted Date: August 13th, 2020

DOI: https://doi.org/10.21203/rs.3.rs-57683/v2

License: (c) (i) This work is licensed under a Creative Commons Attribution 4.0 International License. Read Full License 
The authors have withdrawn this preprint from Research Square 